\title{
T11 Vertebra
}

National Cancer Institute

\section{Source}

National Cancer Institute. I11 Vertebra. NCI Thesaurus. Code C33722.

The eleventh thoracic vertebra counting from the top down. 